\title{
Skeletal Muscle Changes Following Myelotomy in Paraplegic Patients
}

\author{
R. Scelsi, ${ }^{1}$ P. Poggi, ${ }^{2}$ R. Padovani, ${ }^{3}$ S. Lotta, ${ }^{4}$ S. Cairoli ${ }^{5}$ and A. Saitta ${ }^{4}$ \\ ${ }^{1}$ Istituto di Anatomia ed Istologia Patologica, Laboratorio di Neuropatologia. \\ Università di Pavia, Italy. ${ }^{2}$ Istituto di Istologia ed Embriologia Generale, Università \\ di Pavia, Italy. ${ }^{3}$ Divisione di Neurochirurgia. Ospedale Bellaria, Bologna, Italy. \\ ${ }^{4}$ Centro di Recupero e Rieducazione Funzionale 'G. Verdi' USSL N. 3, Villanova \\ sull'Arda, PC, Italy. ${ }^{5}$ Clinica Neurologica, Università di Pavia, Italy.
}

\section{Summary}

Pourpre's dorsal T-shaped myelotomy was performed on three paraplegic patients in which medical and electro-physiological procedures proved to be ineffective concerning muscle spasms.

The myelotomy led to the elimination of spasms and of muscle hypertonicity in the lower limbs.

Biopsies of the rectus femoris muscles were performed bilaterally one year before and two months following myelotomy. The first biopsy revealed fascicular atrophy, with type I fibre preferential atrophy, which is usually found in paraplegic patients.

After myelotomy some histological differences were seen: reduction of type II fibre diameter and the presence of target-targetoid fibres and of atrophic dark fibres.

There was a difference of fibre pattern type in hypertonic spastic muscles compared to that seen in spasm relieved by myelotomy.

The morphological changes seen after myelotomy are interpreted as denervation changes because of the surgical lesion by the myelotomy on the anterior horn cells.

Key words: Paraplegia; Treatment of spasticity; Myelotomy; Skeletal muscle morphology.

Spasticity is a hyper-excitable state of spinal cord reflexes gradually appearing after the initial phase of spinal trauma, about one or two months after the injury.

Excessive spasticity, painful spasms or subsequent contractions often occur in paraplegic patients, interfering with their rehabilitation and resulting in gradual deterioration of the patients' condition. When medical and electrophysiological procedures are ineffective, the management of spasticity and pain can be achieved by surgical myelotomy. (Pourpre, 1960; Laitinen et al., 1971; Ivan et al., 1975; Padovani et al., 1982; Gros et al., 1967; Yamada et al., 1976; Ivan et al., 1975).

Alterations of muscle fibre morphology and distribution were recently

Address for correspondence: Prof. R. Scelsi, Istituto di Anatomia Patologica, Via Forlanini 1427100 Pavia, Italy. 
described in patients with traumatic cord lesions at intervals starting from the time of occurrence of the accident (Scelsi et al., 1982).

Three of these patients who had excessive spasticity and pain, underwent a dorsal longitudinal myelotomy. The present study was performed to determine the morphological changes of a lower limb muscle after dorsal longitudinal myelotomy in those patients. Biopsies of the left and right rectus femoris muscles were performed before and after surgery were studied and compared by means of histology, enzyme-histochemistry and electron microscopy.

\section{Patients and Methods}

Three patients (two males and one female) with complete traumatic transection of the cervical or high thoracic dorsal cord segments (C5-T1) underwent a dorsal longitudinal myelotomy one year after the accident, using Pourpre's type of myelotomy (1960).

\section{Surgical Myelotomy}

The technique introduced by Pourpre is a dorsal 'T-shaped' myelotomy. The spinal cord is incised along the posterior median sulcus between L1 and S1. Followed by a bilateral horizontal incision between the anterior and posterior horns. This results in an interruption of the reflex arcs and avoids injury to the corticospinal pathways. (Pourpre, 1960; Padovani et al., 1982).

The operation is carried out under endotracheal general anaesthesia. With the patient in the prone position a bilateral laminectomy from $\mathrm{T} 10$ to $\mathrm{L} 1$ is carried out and the dura is opened in the midline. With the aid of an operating microscope with $16 \mathrm{X}$ magnification, the $\mathrm{S} 1$ root is identified by means of microstimulation (resulting in a plantar flexion of the foot). A myelotomy $5.5 \mathrm{~cm}$ long is made beginning at $\mathrm{S} 1$ and proceeding vertically a 3-mm-deep incision is made along the whole length of the L1-S1 tract following the posterior median sulcus; thus we carried out a T-shaped myelotomy (Fig. 1).

\section{Patients}

(1) GM, a 20-year-old man sustained traumatic spastic tetraplegia because of fracture of C4-C5 in 1981. On admission, there was severe spasticity in all four limbs with scissoring of the legs and complete anaesthesia below the level of T2. He also had painful spasms of the abdominal muscles, and hyperreflexia of the urinary bladder.

A dorsal longitudinal myelotomy was performed one year after the accident, and resulted in complete elimination of spasms in the lower limbs and partially in the abdominal region. The level of anaesthesia was not affected.

It was possible to move the patient from bed to a wheelchair, 15 days after surgery.

(2) GMA, a 30-year-old man had a cervical spinal trauma (C7) in 1981.

On admission, he had spastic flexion paraplegia with hyperadduction and painful spasms in the lower limbs, bladder paralysis, and complete anaesthesia below T7. A T-shaped longitudinal myelotomy was performed in 1983, with abolition of spasms the patient was able to sit in a wheelchair. The level of anaesthesia was unchanged. 


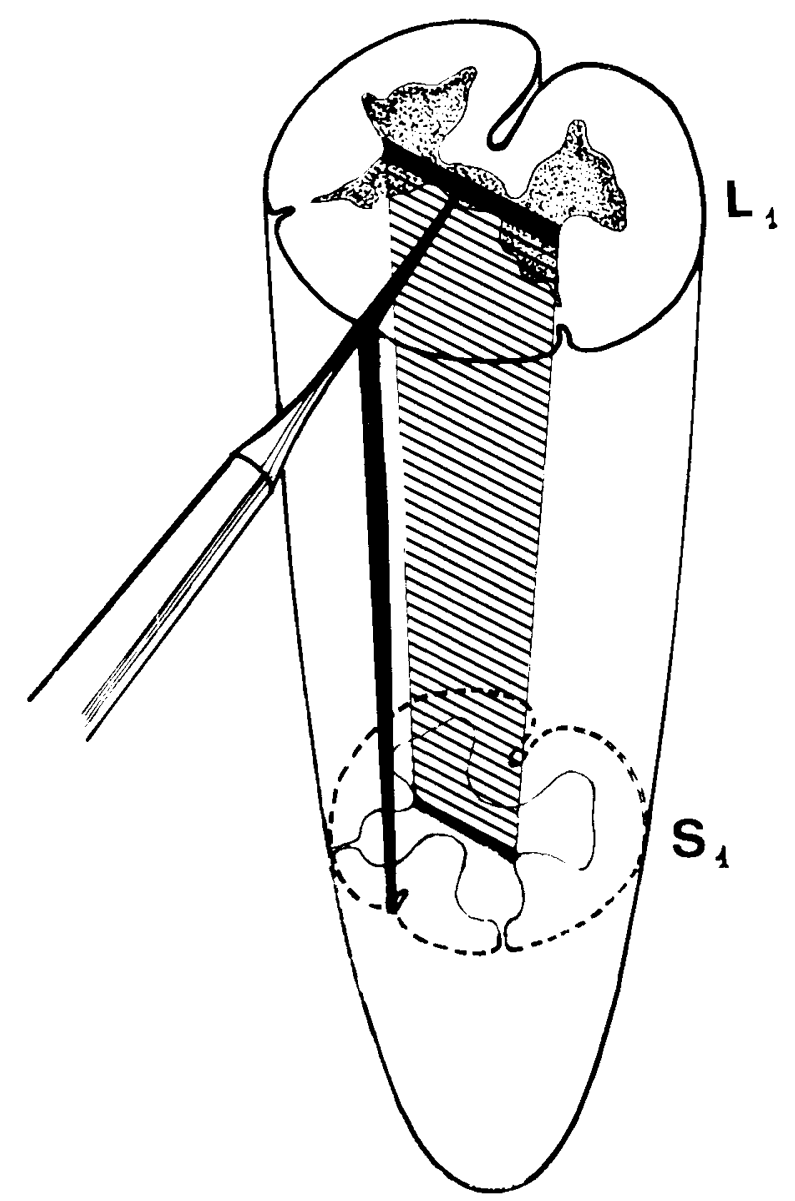

Figure 1. Pourpre's T-shaped myelotomy (drawing from Ivan-Wiley, 1975 with modifications).

(3) PA, a 50-year-old woman had an operation for herniation of the T7/T8 intervertebral disc which had caused a complete spinal cord lesion in 1981 . There was complete anaesthesia below T10 level. A spastic paraplegia with painful spasms in the lower limbs and bladder hyperreflexia. In 1983, the patient underwent a $\mathrm{T}$-shaped longitudinal myelotomy. The result was an immediate abolition of muscle hypertonicity and of painful spasms, with possibility of the patient transferring from bed to wheelchair. The level of anaesthesia was unchanged.

\section{Electrophysiology}

In all patients electromyographic studies were performed 2 months before and 30 days after myelotomy. The presence of spontaneous activity was studied in the rectus femoris muscles at rest. $\mathrm{M}$ max and $\mathrm{H}$ max responses of the same muscle were evoked, and the $\mathrm{H} \max / \mathbf{M} \max$ ratio was calculated. Bulbo cavernosus muscle responses were also studied. Sensory evoked potentials (SEP) obtained by stimulation of the posterior tibial nerve were examined before and after myelotomy. 


\section{Muscle Biopsies}

Muscle biopsies ( $1 \mathrm{~cm}$ in length and $0.50 \mathrm{~cm}$ in diameter), were taken from the mid-portion of the right and left rectus femoris muscles, and each was divided into three portions. Two were fixed in $10^{\circ}$ o neutral formalin and in Karnovsky fluid respectively, and then processed for histol and electron-microscopy. The last specimen was frozen in isopentane cooled in liquid nitrogen and serial cryostat transverse sections of about $8 \mathrm{~mm}$ thick were stained with the modified Gomori trichrome stain, PAS and Oil red 0. Fibre typing was performed using myosin ATP ase, pH 9.4 and 4.6 and by DPNH-diaphorase. The muscle fibre diameter was determined by measuring in transverse sections the shortest diameter of 200 fibres from each specimen stained for ATPase activity. Measurements were made by an automatic image analyser IBAS-ZEISS-Kontron.

Histograms of type I and type II muscle fibres were obtained for each case. Results in text and table are given as a mean with standard deviation (SD). For each case, the T-test was calculated for comparison of the fibre types, before and after myelotomy.

\section{Results}

\section{Electrophysiology}

The electrophysiological finding concerning the presence of fibrillation activity in the rectus femoris muscle, the $\mathrm{Hmax} / \mathrm{Mmax}$ ratio, and the bulbo cavernosus muscle reflex response, are summarised in Table 1 . The increase of the fibrillation

Table 1 Electrophysiological findings before and after myelotomy procedures in paraplegic patients

\begin{tabular}{lccccc}
\hline Case & Time & $\begin{array}{c}\text { Fibrillation Activity } \\
\text { (2 points on 5) }\end{array}$ & $\begin{array}{c}\text { Hmax/Mmax } \\
\text { ratio } \\
\text { (n: } 0.3-0.8)\end{array}$ & $\begin{array}{c}\text { Reflex Response in } \\
\text { Bulbo-cavernosus } \\
\text { Muscle }\end{array}$ & SEP \\
\hline GM & Before & Present & 10 & Present & Absent \\
& After & Increased & $3 \cdot 2$ & Present & Absent \\
GMA & Before & Present & 5 & Present & Absent \\
& After & Increased & $1 \cdot 6$ & Present & Absent \\
PA & Before & Present & $3 \cdot 2$ & Present & Absent \\
& After & Increased & $1 \cdot 1$ & Present & Absent \\
\hline
\end{tabular}

activity of the rectus muscle and the decrease of the Hmax/Mmax ratio after myelotomy is seen in all the patients. SEP were absent both before and after myelotomy.

\section{Histopatology}

The main morphological and enzyme histochemical findings observed in the left and right rectus femoris muscles respectively before and after myelotomy are summarised in Table 2.

In case GM, before myelotomy there was muscle atrophy, with presence of some small atrophic rounded fibres, occasionally angulated. The muscle fibre typing showed a normal distribution and frequency of fibre types and type I preferential atrophy. No myopathic changes were seen. Electron microscopy 
Table 2 Fibre type percentages and diameters (mean \pm SD) and morphological findings in muscle biopsies of paraplegic patients one year before (A) and two months after (B) myelotomy

\begin{tabular}{|c|c|c|c|c|c|c|c|}
\hline \multirow[t]{2}{*}{ Patient } & \multirow[t]{2}{*}{ Age } & \multirow{2}{*}{$\begin{array}{l}\text { Biopsy } \\
\text { Performed }\end{array}$} & \multirow{2}{*}{$\begin{array}{l}\text { Fibre } \\
\text { Type I } \\
0\end{array}$} & \multicolumn{2}{|c|}{ Fibre diameter $(\mu \mathrm{m})$} & \multirow[t]{2}{*}{ Structural Changes } & \multirow[t]{2}{*}{ Electron Microscopy } \\
\hline & & & & Type I & Type II & & \\
\hline GM & 20 & $\begin{array}{c}\text { A } \\
\text { B } \\
\text { AvsB, } P<\end{array}$ & $\begin{array}{l}50 \\
48\end{array}$ & $\begin{array}{c}18 \cdot 33 \pm 3 \cdot 05 \\
18 \cdot 40 \pm 3 \cdot 10 \\
\text { NS }\end{array}$ & $\begin{array}{c}22 \cdot 20 \pm 3 \cdot 48 \\
16 \cdot 0 \pm 2 \cdot 20 \\
P<0 \cdot 01\end{array}$ & $\begin{array}{l}\text { Dark angular fibres } \\
\text { Target fibres } \\
\text { Internal nuclei }\end{array}$ & $\begin{array}{l}\text { Myofibrillary changes } \\
\text { Sarcoplasmic masses } \\
\text { Target fibres } \\
\text { Changes of sarcoplasmic } \\
\text { reticulum }\end{array}$ \\
\hline GMA & 30 & $\begin{array}{c}\text { A } \\
\text { B } \\
\text { AvsB, } P<\end{array}$ & $\begin{array}{l}65 \\
85\end{array}$ & $\begin{array}{c}19 \cdot 60 \pm 3 \cdot 46 \\
18 \cdot 0 \pm 2 \cdot 60 \\
\text { NS }\end{array}$ & $\begin{array}{c}20 \cdot 0 \pm 3 \cdot 00 \\
18 \cdot \pm 3 \cdot 20 \\
P<0 \cdot 01\end{array}$ & $\begin{array}{l}\text { Small group atrophy } \\
\text { Dark angular fibres } \\
\text { Internal nuclei }\end{array}$ & $\begin{array}{l}\text { Myofibrillary changes } \\
\text { and rods formation. }\end{array}$ \\
\hline PA & 50 & $\begin{array}{c}\text { A } \\
\text { B } \\
\text { AvsB, } P<\end{array}$ & $\begin{array}{l}46 \\
28\end{array}$ & $\begin{array}{c}19 \cdot 8 \pm 3 \cdot 05 \\
18 \cdot 2 \pm 2 \cdot 02 \\
\text { NS }\end{array}$ & $\begin{array}{c}24 \cdot 6 \pm 2 \cdot 60 \\
20 \cdot 0 \pm 2 \cdot 20 \\
P<0 \cdot 01\end{array}$ & $\begin{array}{l}\text { Focal myopathic } \\
\text { changes } \\
\text { Dark angular fibres } \\
\text { Clumps of pycnotic } \\
\text { nuclei. Myopathic } \\
\text { changes }\end{array}$ & $\begin{array}{l}\text { Myofibrillary changes } \\
\text { and rods formation } \\
\text { Small light fibres } \\
\text { with prominent nuclei } \\
\text { 'Regenerating fibres' } \\
\text { Micropycnocytosis }\end{array}$ \\
\hline
\end{tabular}




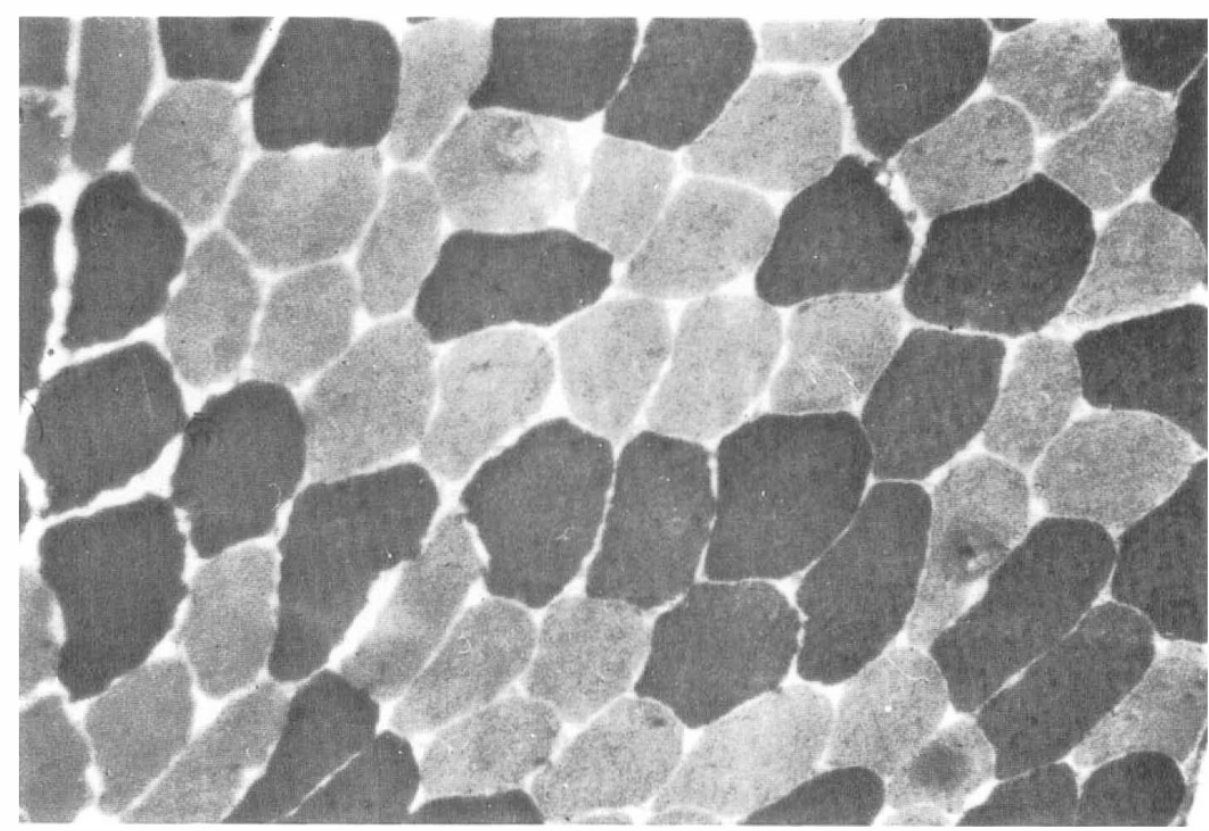

Figure 2. Muscle atrophy with type I fibre predominance and preferential atrophy. ATP-ase pH 9.4; 250X Case GMA. Biopsy before myelotomy.

revealed some alterations in atrophic fibres, consisting in myofibrillary disorganisation with evidence of sarcoplasmic masses containing glycogen granules and lipid droplets.

After myelotomy biopsy of the controlateral muscle revealed groups of atrophic angulated fibres, many target-targetoid fibres $\left(18^{\circ}{ }_{0}\right)$ with a pale staining centre (Fig. 3) and scattered hypertrophied fibres with internal nuclei. The muscle fibre typing showed numerous type II fibres of smaller diameter than type I. The reduction in diameter was significant if compared with the biopsy performed before surgery. Some hypertrophied type I fibres were seen.

Ultrastructural investigation showed many fibres with target or targetoid appearance, with central areas demonstrating myofibrillary degeneration and disorganisation with rod formation. Dilatation and reduplication of sarcoplasmic reticulum was seen in numerous fibres.

Case GMA. The initial biopsy showed muscle atrophy, with presence of atrophic rounded fibres. Perifascicular fatty infiltration was also evident. Abnormalities of fibre type distribution were characterised by moderate type I fibre predominance and atrophy (Fig. 2).

These fibres showed ultrastructural patterns of extensive degeneration with myofibrillary disruption and rod formation. A frequently noted abnormality was the lipofuscin osmiophilic particles accumulated in the sarcoplasm of the muscle fibres.

The post-myelotomy biopsy showed increased variability of fibre size, with small group fibre atrophy. Numerous fibres revealed nuclear internalisation and scattered ones demonstrated degeneration and simple necrosis. Enzyme histo- 


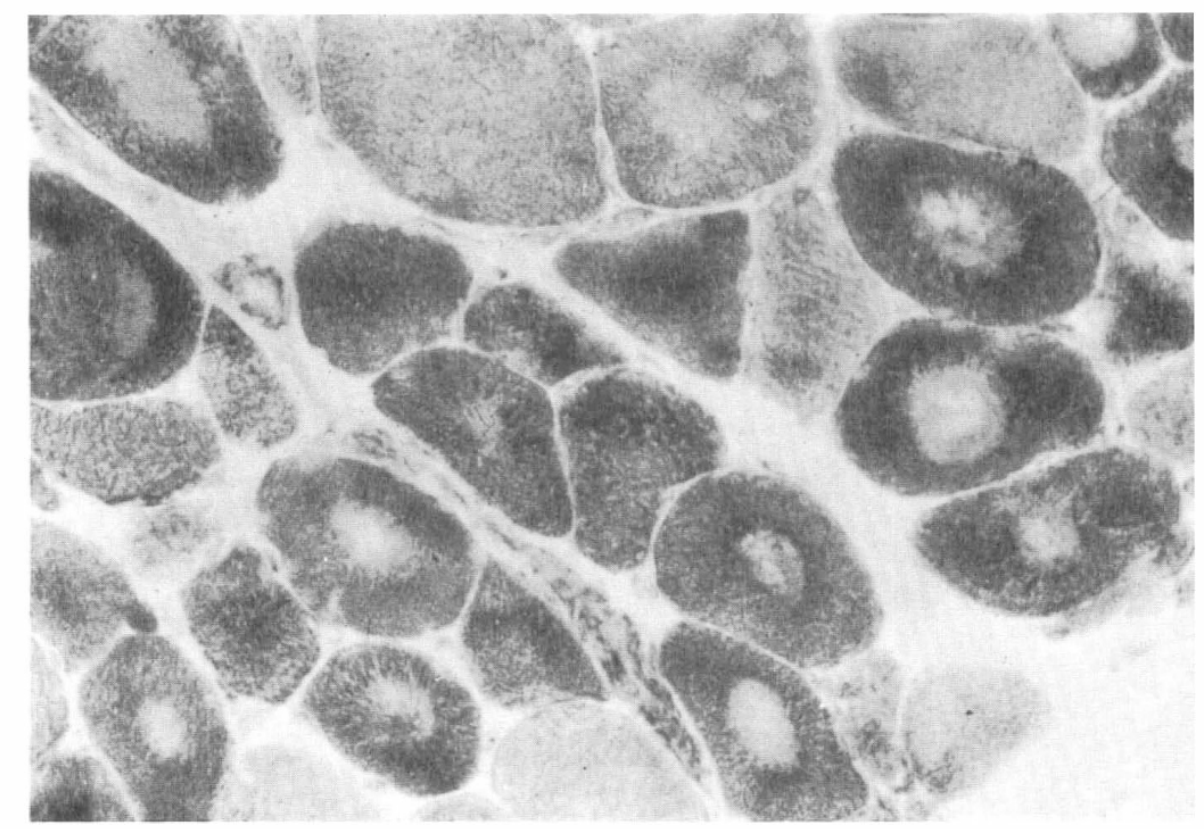

Figure 3. Groups of atrophic fibres and target targetoid aspects. DPNH-d, 400X. Case GM. Biopsy after surgery.

chemical reactions revealed a significant reduction of type II fibres compared with the histochemical appearances seen before surgery. Atrophic angular fibres $(20 \%)$ with a dark appearance due to an abnormally increased reaction for oxidative enzymies (Fig. 4), were seen. Electron microscopic studies revealed numerous small atrophic fibres with pale appearance characterised by loss of myofibrills and by numerous adjacent central nuclei containing light grey chromatin and a prominent nucleolus. Micropycnocitotic vescicles of plasma membrane of numerous muscle fibres were also seen.

Case PA. The initial biopsy revealed some variations of fibre diameters, with atrophy, hypertrophy and with nuclear internalisation of some fibres. Perymisial fibrosis and perifascicular fatty infiltration were also evident. The presence of many small dark angular fibres was observed, with type I preferential atrophy. Ultrastructural changes consisted in myofibrillary disorganisation with rod formation and in abnormal reduplication of triads. Pycnotic nuclei were frequently seen.

The post-myelotomy biopsy showed fascicular atrophy with increased variability of muscle fibre diameter. Atrophic fibres were predominant and some pycnotic nuclear clumps were seen, as well as some necrotic fibres and hypertrophic ones with internal nuclei. Type II fibre predominance was observed, with the presence of small atrophic fibres $(15 \%)$ intensely stained with oxidative enzymes. Perymisial fibrosis, with an increase of interstitial fatty tissue was also evident. Comparison of the biopsies with regard to fibre diameter revealed a significant reduction of the type II fibre diameter after myelotomy.

Ultrastructural investigations revealed numerous fibres characterised by central nuclei, with prominent nucleoli and by groups of myofibrils interspersed 
between rods and reduplicating triads; a number of these showed micropycnocitotic sarcolemmal vescicles (Fig 5).

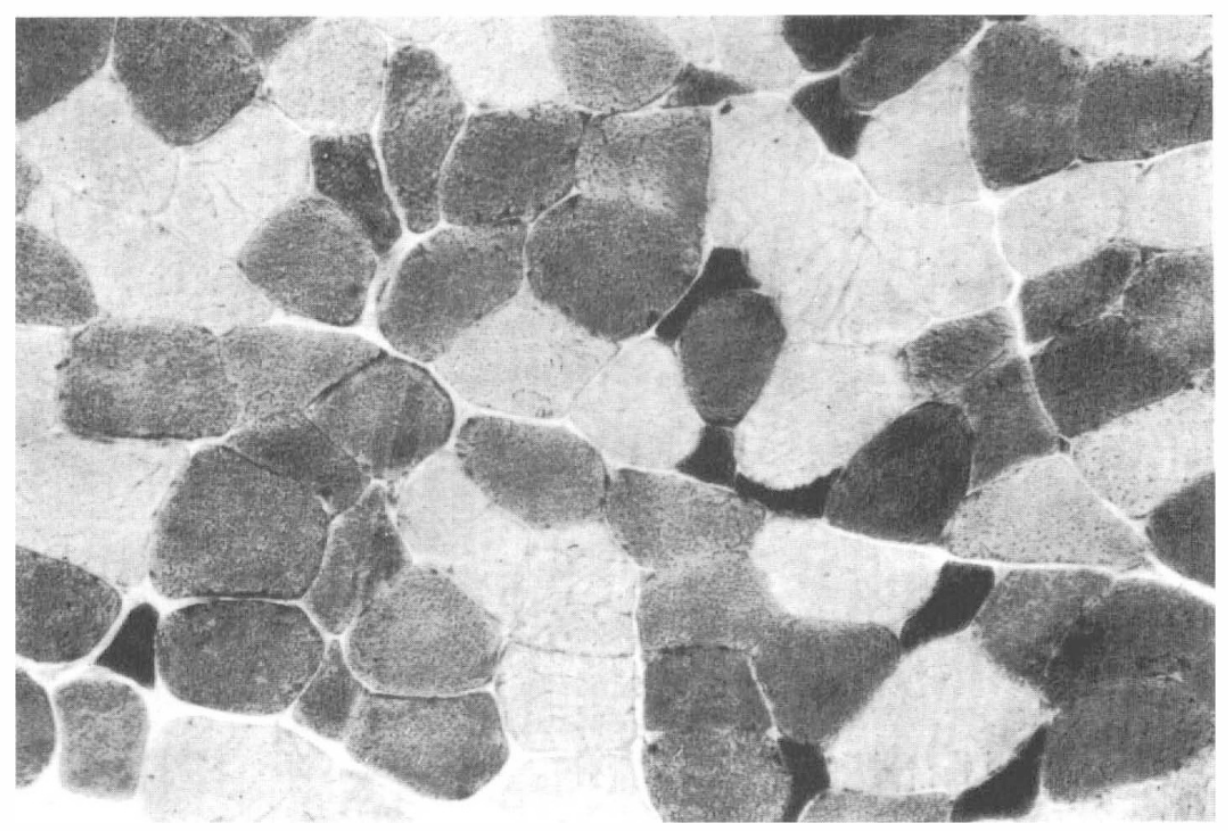

Figure 4. Presence of small atrophic angulated fibres strongly reactive to oxidative enzyme reaction. DPNH-d, 250X. Case GMA. Biopsy after surgery.

\section{Discussion}

Excessive spasticity, painful spasms or subsequently muscle contractions may occur in paraplegic patients, interfering with rehabilitation and resulting in a gradual deterioration of the patients' condition.

Three paraplegic patients with severe spasticity in the lower limbs, underwent a T-shaped dorsal longitudinal myelotomy according to Pourpre (1960). All three patients had abolition of hypertonicity and painful spasms, with no alteration of the previous anaesthesia level. In the present study, some morphological differences between rectus femoris muscle biopsies of paraplegic patients, taken before and after a longitudinal myelotomy are stressed.

Skeletal muscle changes seen in the initial biopsy are similar to those observed in paraplegic subjects with traumatic spinal cord lesions one year after the occurrence of the accident (Scelsi et al., 1982; Lotta et al., 1982). They consisted in muscle atrophy, with marked decrease of muscle fibre diameter. The type I fibres showed a major change with a smaller size in respect to the type II fibres. In one patient, focal myopathic changes were observed. The major ultrastructural changes were myofibrillary disorganisation and dilatation and proliferative phenomena of the sarcoplasmic reticulum and $\mathrm{T}$-system. These changes are considered to be done to various causes, from disuse and derangement of upper 


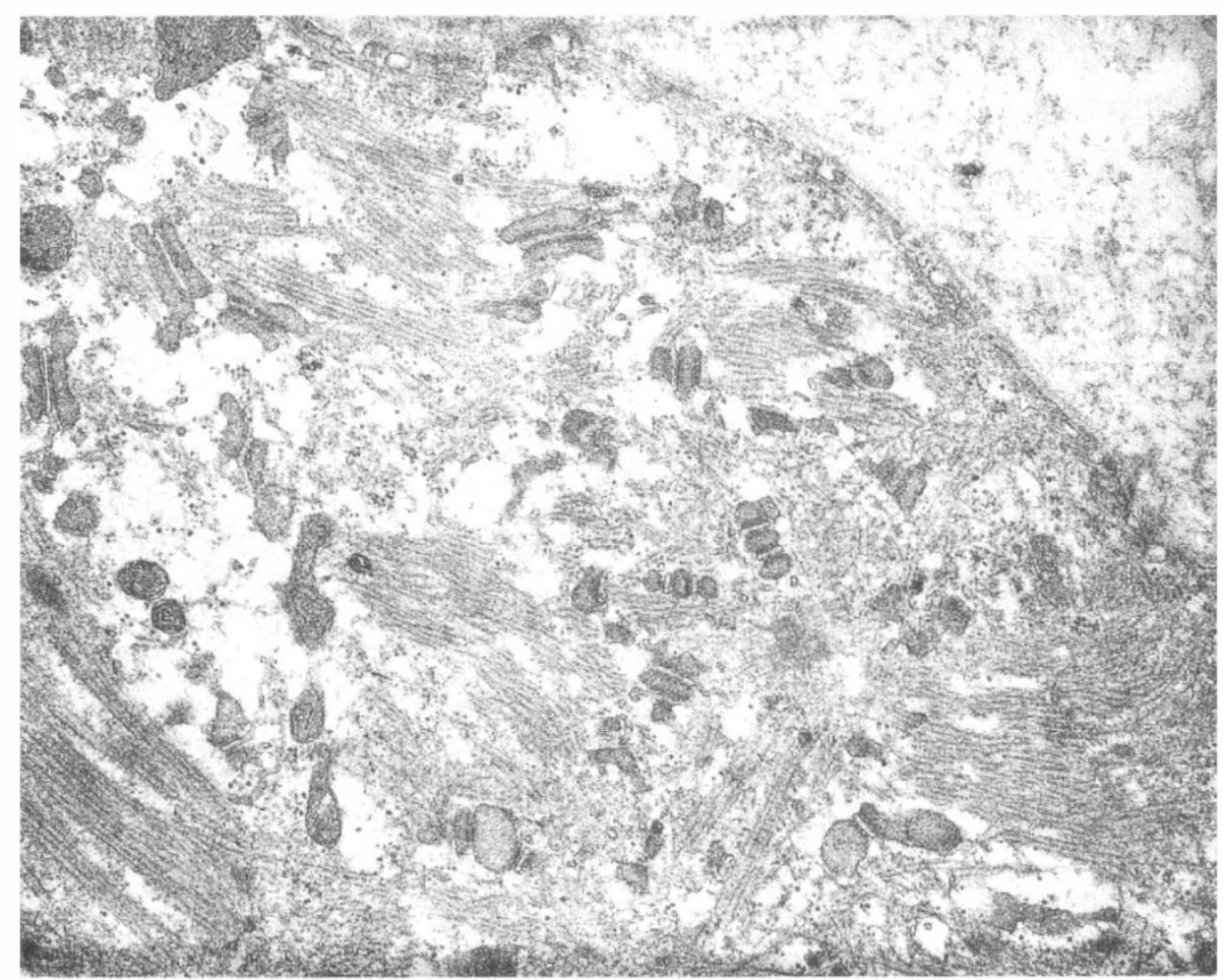

Figure 5. Micropycnocitotic vescicles of plasma membrane in an atrophic fibre. 21.000X.

Case PA.Biopsy after surgery.

motor neuron control on the lower motor neuron (Ochs, 1974; Scarlato et al., 1976; Scelsi et al., 1982).

In the biopsy performed two months after myelotomy on the contralateral muscle, some new muscular changes were superimposed on the previous alterations. These changes in muscle appearance were seen after a destructive operation on the spinal cord and are interesting in order to compare changes seen in spastic muscle with changes in muscle relieved of spasm. Myelotomy produced a significant reduction of type II fibre diameter and some cytoarchitectural changes. In our patients the reduction of type II fibre diameter seems to be the most selective adaptation of muscle fibres relieved of spasm. In muscle pathology the type II fibre atrophy indicates disuse of the muscle from various illnesses and other states in which muscle activity is hampered (Dubowitz and Brooke, 1973).

The main cytoarchitectural change seen in muscle fibres after myelotomy were target and targetoid fibres. These alterations are morphological expressions of denervation, possibly related to incidental lesions that the anterior horn cells underwent during the myelotomy procedure. Electromyographic studies confirmed these denervation findings, demonstrating evident and persistent fibrillation activity of the rectus femoris muscle.

The presence of many small fibres, with internal nuclei and prominent nucleolus and with evident membrane mycropycnocitosis seen only in the later 
biopsy, may be interpreted as degenerating fibres with some regenerative efforts (Mair et al., 1972). The mycropycnocitosis phenomena could be looked upon as the morphological expression of the attempt of the fibre to be reinnervated again.

\section{Résumé}

On a executé la myélotomie dorsale suivant Pourpre sur trois patients atteints de paraplégie, patients sur les quels les soins médicaux et électrophysiologiques ont été inefficaces. La myélotomie tend à eliminer les contractures et l'hypertonie du muscle dans les membres inférieurs. On a fait les biopsies du muscle 'rectus femoris' un mois an avant et deux mois après la myélotomie.

La première biopsie a mis an évidence une atrophye surtout sur les fibres du type I, comme on observe chez les sujets paraplégiques. Après la myélotomie, on a observé quelques différences: réduction du diamètre des fibres du type II avec la présence de fibres 'foncées' atrophyées. Les altérations morphologiques observées après la myélotomie sont interprétées comme des exemples de dénervation secondaire à des lésions chirurgicales imprévues sur les cellules des cornes antérieures.

\section{Zusammenfassung}

Dorsal myelotomie nach Pourpre wurde an paraplegischen Patienten ausgeführt, bei denen klinische und elektrophysiologische Therapie sich als unwirksam erwies. Die Myelotomie neiget, Krämfe und Hypertonie an Muskeln des unteren Gliedes zu beseitigen. Biopsien der Oberschenkel-Rektus wurden ein Jahr vor und zwei Monate nach der Myelotomie durchegeführt. Vor der Myelotomie zeigte die Biopsie eine faszikuläre Atrophie an, das heisst vorzüglich Atrophie der $I^{\circ}$ Typ-Fasern, wie es meistens bei paraplegischen Patienten vorkommt.

Nach der Myelotomie, wurden folgende Unterschiede beobachtet: Verringerung am Durchschnitt der II $^{\circ}$ Typ-Fasern, Vorhandensein von 'target-targetoid'- Fasern und atrophische dunkle Fasern.

Diese nach der Myelotomie beobachteten morphologischen Veränderungen werden als Entnervungsbilder angesehen, die sich im Bereich der Vorderhornzellen wegen chirurgischer Gewebsschädigung sekundär entwickeln.

\section{References}

Benedetti A, Carbonin C, Curri D, et al. 1977 Longitudinal lumbar myelotomy for spastic paraplegia. Journal of Neurosurgery 22:1-10.

Gros C, Ouaknine G, Vlahovitch B, et al. 1967 La radicotomie sélective posterieure dans la traitement neurosurgical de l'hypertonie pyramidale. Neurochirurgie 13:505-518.

IVAN LP, WILEY JJ 1975 Myelotomy in the management of spasticity. Clinical Orthopaedics 108:52-56.

Laitinen L, Singounas E 1971 Longitudinal myelotomy in the treatment of spasticity of the legs. Journal of Neurosurgery 35:536-540.

Lotta S, Lommi G, Marchetti C, et al. 1982 Muscle fibre morphology in paraplegic patients with traumatic cord lesions. In: First Int. Workshop in para and tetraplegia. Milan, 10-12 Dec. 1982 Abst. p. 59.

MAIR WGP, TOME FMS 1972 Atlas of the ultrastructure of diseased human muscle. Churchill Livingstone: Edinburgh and London, p. 198.

OchS S 1974 System of material transport in nerve fibers (axoplasmic transport) related to nerve function and trophic control. Annals of the New York Academy of Sciences 228:202-210.

Padovani R, Tognetti F, Pozzati E, et al. 1982 The treatment of spasticity by means of dorsal longitudinal myelotomy and lozenge-shaped griseotomy. Spine 7:103-109.

PouRPRE MH 1960 Traitement neurochirurgical des concranctures chez les paraplégiques post-trumatiques. Neurochirurgie 6:229-236.

Scarlato G, Valli G, Pagni G, et al. 1976 L'amitrofia spinale nelle sindromi apalliche. Acta Neurology 21:62-67.

Scelsi R, Marchetti C, Poggi P, et al. 1982 Muscle fiber type morphology and distribution in paraplegic patients with traumatic cord lesions. Acta Neuropath. (Berl) 57:243-248.

YAMADA S, Perot PL, DuCKer TB, et al. 1976 Myelotomy for control of mass spasms in paraplegia. Journal of Neurosurgery 45:683. 